\title{
Piezoelectric and Dielectric Properties of PZT-Epoxy Composite Thick Films
}

\author{
Sundar $\mathbf{U}^{1}$, Banerjee $\mathrm{S}^{2}$ and Cook-Chennault $\mathrm{KA}^{3 *}$ \\ ${ }^{1}$ Portland Technology Development, Intel Corporation, USA \\ ${ }^{2}$ Department of Mechanical Engineering, California State University, USA \\ ${ }^{3}$ Department of Mechanical and Aerospace Engineering, Rutgers the State University of New Jersey, USA
}

Submission: September 06, 2018; Published: October 04, 2018

*Corresponding author: Cook-Chennault KA, Department of Mechanical and Aerospace Engineering, Rutgers the State University of New Jersey, New Jersey, USA, Email: cookchen@soe.rutgers.edu

\begin{abstract}
Composite piezoelectric thick films are envisioned for energy harvesting, energy storage, and advanced sensor applications. This work focuses on PZT-epoxy-aluminum thick films that were fabricated using a two-step spin coat deposition and annealing method. The volume fraction of the PZT filler ranged from 0.2 to 0.4 , and the aluminum volume fraction was varied from 0.10 to 0.17 for each PZT volume fraction, respectively to ascertain the percolation range of the devices and the influence of the aluminum on the device piezoelectric and dielectric properties. An aluminum filler was included in the PZT-epoxy composite to enhance the polarization process of the composite and to enhance the dielectric properties of the composite. The piezoelectric strain coefficients $\mathrm{d} 33$ and $\mathrm{d} 31$, and capacitance were measured and studied as a function of aluminum volume fraction and top electrode material (silver and gold). It was determined that beyond a critical volume fraction of aluminum, the aluminum particles formed conductive pathways within the composite (percolation threshold region) which diminished piezoelectric strain coefficients beyond the percolation threshold value. The percolation thresholds for these samples were found to occur from 0.13 and 0.17 volume fraction of aluminum, which agrees with theoretical predictions. SEM micrographs were used study the interactions between various phases of the composite.
\end{abstract}

Keywords: Aluminum; Thick films; Silver; Biomedical

Abbreviations: MOD: Metal Organic Decomposition; MOCVD: Metal Organic Chemical Vapor Deposition; PLD: Pulsed Laser Deposition; SEM: Scanning Electron Microscopy

\section{Introduction}

Ferroelectric films have been of interest over the last 20 years because of the possibility of using them for non-volatile memory applications [1-3], MEMS [4-6], ultrasonic devices [4,7], battery separators [8-10], biomedical scaffolds [11] and energy harvesting devices where they are coupled with batteries [12]. The properties if piezoelectric films cannot be compared directly with those of bulk materials of the same composition because their processing and electrical properties differ. Previous work on the preparation of piezoelectric films includes RF planar magnetron sputtering $[13,14]$, ion beam sputtering [15] or DC magnetron sputtering [16], where most recently, researchers have succeeded in fabricating films using various chemical methods of deposition such as; metal organic chemical vapor deposition (MOCVD) [17- 19], chemical solution deposition [20,21], metalorganic decomposition (MOD) [22,23], and also pulsed laser deposition (PLD) [24-26]. The sol-gel method has the benefits of compositional control, reduced temperature processing of highly uniform, dense, crack-free films and low cost of fabrication $[27,28]$. These methods of processing ferroelectric films have been used with notable success to produce piezoelectric ceramic films comprised of Lead Zirconate Titanate $\left(\mathrm{PbZr}_{x} \mathrm{Ti}_{1-\mathrm{X}} \mathrm{O}_{3}\right.$ also known as, PZT). PZT has a high dielectric constant, ferroelectric, piezoelectric, and pyroelectric properties. The ideal properties of PZT have made its application to transducer, sensor and actuator devices ubiquitous. However, the poor mechanical strength of these devices has limited their life cycle and performance. Therefore, interest in polymer-ceramic [29-33] (and ceramicceramic $[34,35])$ composites has emerged as an area of interest because polymers are flexible, low cost, easily processed [36,37] and able to be polarized under the influence of an external electric field [38].

Piezoelectric ceramic/polymer composites possessing various connectivity patterns have been the focus of much study over the past several years $[34,35,39-42]$. Among the composites examined, the simplest types are those with $0-3$ connectivity $[39,43]$. Piezoelectric composites with 0-3 connectivity consist of piezoelectric ceramic particles dispersed in a three dimensionally connected matrix [1, 5, 29-32, 34, 35, 44-48]. The advantages of 
these composites lie in the ease in which they may be processed into fairly complex shapes, including but not limited to thin sheets, molded shapes and extruded bars and fibers [39]. The most documented of piezoceramics used in composites such as these is PZT [4, 20, 42, 49-52].

Banerjee et al., [34] studied the influence of aluminum inclusions on the dielectric properties of three-phase PZT cement aluminum composites, where the aluminum and PZT particles were dispersed in a Portland cement matrix. The fabricated samples were nominally $6 \mathrm{~mm}$ in thickness and were poled at a low poling voltage of $0-6 \mathrm{kV} / \mathrm{mm}$ at a temperature of $160{ }^{\circ} \mathrm{C}$ in air. It was reported that three-phase composites possessed a higher piezoelectric strain coefficient $\left(\mathrm{d}_{33}\right)$ than two-phase composites. The highest value of ${ }_{\mathrm{d} 33}$ observed for the three-phase composite was $8.1 \mathrm{pC} / \mathrm{N}$ for volume fractions equal to 0.7 and 0.2 for PZT and Al, respectively. This $d_{33}$ value for the three-phase piezoelectric composite was 1.64 times the value measured for the two-phase composite. Banerjee et al., [53] also investigated the influence of micro and nano sized aluminum inclusions in a three-phase PZT-Epoxy-Al bulk composite. The fabricated composites were $\sim 6 \mathrm{~mm}$ thick and were comprised of micron sized aluminum powder and PZT. These devices had higher dielectric constants that the composites that incorporated nanosized aluminum particles (both sets of samples were polarized at the same value: $0.2 \mathrm{kV} / \mathrm{mm}$ in air) due to interfacial effects, contact resistance and increased agglomeration. Specifically, for composites with PZT volume fractions equal to $0.20,0.30$ and 0.40 and micron- sized aluminum particles, the dielectric constants were equal to 405.7, 661.4 , and $727.8(\mathrm{pC} / \mathrm{N})$, respectively. On the other hand, the dielectric constants for composites that were comprised of nano sized aluminum particles the (the same PZT volume fractions) dielectric constants were equal to $233.28,568.81$, and 657.41 $(\mathrm{pC} / \mathrm{N})$, respectively. They concluded that samples that contained micron sized aluminum inclusion yielded higher dielectric constant values compared to the Nano sized aluminum inclusions, which resulted in higher dielectric values for samples with micron sized piezoelectric fillers.

In this work, PZT-aluminum-epoxy thick film composites were fabricated where the volume fractions of PZT and Al were varied from 0.20 to 0.40 (increments of 0.10 ) and 0.0 to 0.17 , respectively. A minimum of three samples were fabricated for each of the studies. In addition, two different types of top electrodes (sputtered gold and silver paint) were prepared and compared in terms of piezoelectric and dielectric constants. The change in the piezoelectric and dielectric properties with respect to time was also observed over a five-day period.

\section{Materials and Methodology}

The materials used in all experiments were PZT powder (READE), DGEBA Epofix TM Cold-Setting embedding resin (Electron Microscopy Sciences) [54], and aluminum -99.97\%, 200 mesh i.e. $\sim 75 \mu \mathrm{m}$ (Acros Organics) and $0.0254 \mathrm{~mm}$ stainless steel substrates (Alfa Aesar). The piezoelectric and physical properties of the materials are presented in Table $1 \& 2$, respectively. The properties for the aluminum were obtained from the manufacturer website [55,56].

Table 1: Physical and dielectric properties of PZT powder were provided by the manufacturer [56].

\begin{tabular}{|c|c|}
\hline \multicolumn{2}{|c|}{ PZT Properties } \\
\hline Average particle diameter $\left(\mathrm{x} 10^{-}\right) \textrm{m}$ & $6-7$ \\
\hline Density $\left(\mathrm{g} / \mathrm{cm}^{3}\right)$ & $7.6-8.0$ \\
\hline Young's Modulus $\left(\mathrm{x} 10^{10} \mathrm{~N} / \mathrm{m}^{2}\right)$ & $5.8-9.0$ \\
\hline Curie Temperature $\left({ }^{\circ} \mathrm{C}\right)$ & $170-360$ \\
\hline Relative Dielectric Constant, $\varepsilon r$ & 1275 \\
\hline $\begin{array}{c}\text { Piezoelectric Strain Coefficient, } \mathrm{d}_{33} / \mathrm{d}_{31}(10- \\
12 \mathrm{C} / \mathrm{N})\end{array}$ & $\mathrm{d}_{33}=290 / \mathrm{d}_{31}=-125$ \\
\hline Electrical Resistivity $(\mathrm{ohm}-\mathrm{cm})$ & $0.15 @ 1 \mathrm{kHz}$ \\
\hline
\end{tabular}

Table 2: Physical, dielectric and piezoelectric properties of the epoxy and aluminum $[54,55]$.

\begin{tabular}{|c|c|}
\hline Property & DGEBA - Epoxy \\
\hline Relative dielectric constant, $\varepsilon r$ & $2.9-3.7$ \\
\hline Dielectric dissipation, $\tan \delta$ & $\sim 0.02-0.04-1.8$ \\
\hline Electromechanical coupling, $\mathrm{k}_{\mathrm{p}} / \mathrm{k}_{33}$ & -- \\
\hline Piezoelectric charge constant, $\mathrm{d}_{33}(10-12 \mathrm{C} / \mathrm{N})$ & $12.28^{*}$ \\
\hline Young's Modulus, $Y_{11}^{E} / Y_{33}^{E}\left(10^{10} \mathrm{~N} / \mathrm{m}^{2}\right)$ & $0.15-0.20$ \\
\hline Density $\left(\mathrm{g} / \mathrm{cm}^{3}\right)$ & $1.6-1.8$ \\
\hline Electrical Resistivity $(\mathrm{ohm}-\mathrm{cm})$ & $1.16 \mathrm{~g} / \mathrm{cm}^{3}(\mathrm{in} \mathrm{the} \mathrm{wet-state)}$ \\
\hline
\end{tabular}

*Experimental values

PZT epoxy aluminum thick composite films were deposited onto stainless steel substrate using a spin coat and deposition technique. The stainless-steel squares were $25 \mathrm{~mm} \times 25 \mathrm{~mm}$ and $0.0254 \mathrm{~mm}$ thick. An overview of the fabrication process for the devices is provided in Figure 1. The volume fractions of the PZT and aluminum were varied from 0.20 to 0.40 and 0.01 to 0.17 , respectively. As shown in Figure 1, the PZT, aluminum and epoxy were weighed to achieve the desired volume fraction and then 
combined in a beaker. The contents in the beaker were hand stirred for 5 minutes and $5 \mathrm{ml}$ of ethanol was added to this mixture. The mixture was subsequently sonicated in an ultra sonicator for 1 hour, while being hand stirred every 15 minutes. The epoxy hardener was then added to the mixture. The final compound was then poured onto the stainless-steel substrate using a dropper while the spin coater was rotated from 100 - 500rpm for 30 seconds, and subsequently by $1000 \mathrm{rpm}$ for 60 seconds. The initial low rpm enabled an even distribution of the compound over the substrate.

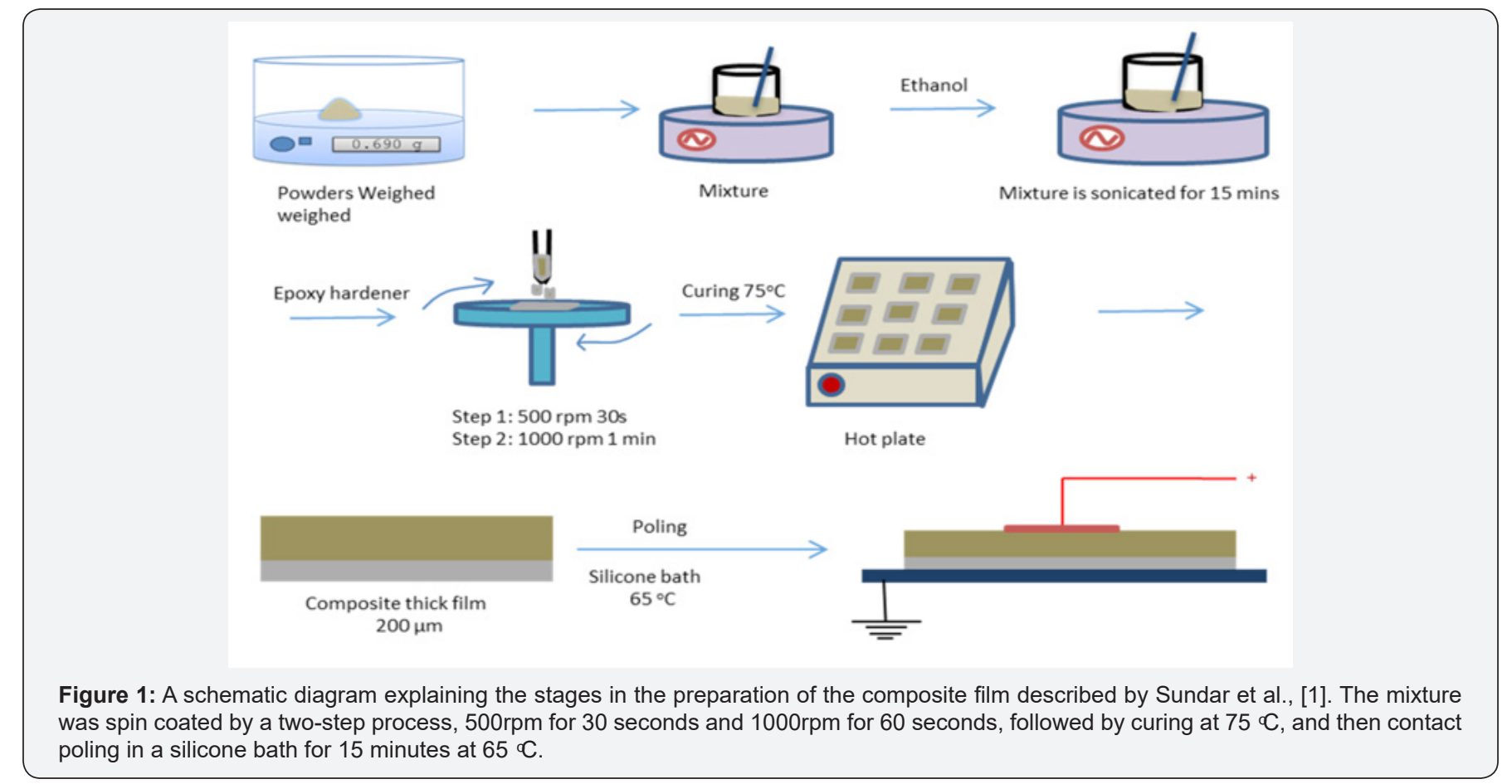

After the spin coating process, the samples were removed and cured on a hot plate in the presence of air for 8 hours at $75{ }^{\circ} \mathrm{C}$. The samples were then cooled for 24 hours and eventually coated with colloidal silver paint as the top electrode. Samples were then contact poled at a voltage of $2.2 \mathrm{kV} / \mathrm{mm}$ at $65{ }^{\circ} \mathrm{C}$ in a silicone oil bath for 15 minutes. An additional set of samples were prepared, where the volume fractions of PZT and aluminum were 0.3 and 0.05 , respectively. Sputtered gold was used as the top electrode for these samples instead of colloidal silver paint. All samples were then wrapped in aluminum foil and stored at room temperature in the air for

24 hours to remove any remaining residual charges that may be on the samples.

\section{Dielectric and piezoelectric characterization}

The piezoelectric strain coefficients, $\mathrm{d}_{33}$ and $\mathrm{d}_{31}$, and capacitance, were measured using a Piezo Meter System manufactured by Piezo Test, Piezoelectric Materials \& Device Testing Company, while the resistance was obtained using an Impedance/Gain Phase Analyzer $\left(\mathrm{HP}_{4194} \mathrm{~A}\right)$. All the measurements were taken after polarization of the sample. The dielectric constant was calculated using the expression,

$$
\varepsilon_{r}=\frac{C t}{A \varepsilon_{o}}
$$

In Equation (1), is the capacitance in Farads, $\mathrm{A}$ is the area of the sample, is the permittivity of free space $\approx 8.854 \times 10 \mathrm{e}-12 \mathrm{Fm}^{-1}$; and $t$ is the thickness of the sample. The impedance analyzer was used to measure the real part of the resistance, $R$, of each sample, and the resistivity was determined from Equation (2),

$$
\rho=\frac{R A}{t}
$$

\section{Material morphology and surface characterization}

The surface morphology of the individual phases and the composite was examined using scanning electron microscopy (SEM) micrographs. Two types of images were gathered for these composites, one was from the top surface of the sample, which provides information about the distribution of the individual phases within the polymer matrix, and the other was the crosssectional image along the thickness of the sample. The crosssectional image represents how the particles are distributed along the thickness and a macroscopic view of the composite substrate interface.

\section{Results and Discussion}

\section{Surface morphology}

The surface morphology of the composite films and the particle distribution within the composite were observed via scanning electron microscopy (SEM) and energy dispersive X-ray spectroscopy (EDS) micrographs. PZT epoxy-aluminum samples that were comprised of $0.30 \mathrm{PZT}$ and 0.09 aluminum (by volume fraction) were observed.

The cross-sections of the samples were obtained by cutting the sample using a blade and placing the samples onto the SEM 
stud to reveal the samples cross-sectioned thickness or surface morphology.

In Figure 2, a SEM micrograph of the cross-section of the film is presented at $467 \times$ magnification. There do not appear to be any microscopic pores or delamination points at the interface between the substrate and the film. In Figure 3, the surface morphology of the composite film is depicted at a magnification of $520 \mathrm{X}$. PZT and aluminum particle agglomeration are observed in this SEM micrograph. The agglomeration may be attributed to several mechanisms of agglomeration, e.g. Brownian, gravitational, turbulent, and electrostatic, where the gravitational form could be mitigated $\mathrm{n}$ theory by the spin coating process. The as received
PZT and aluminum powders tend to naturally form clusters that vary between $5-20 \mu \mathrm{m}$ in the case of aluminum and $10-25 \mu \mathrm{m}$ in the case of PZT as shown in Figure 4A and Figure 4B, where these agglomerations are most likely attributed to electrostatic agglomeration. Though ethanol was used to change the surface charge of the powder particles, its addition did not effectively change the $\mathrm{pH}$ of the solution to negate the surface charge on the all of the particles, which diminished its effectiveness in counteracting the electrostatic forces between particles. The extent of the effective- ness of the ethanol on the $\mathrm{pH}$ of the solution was also a function of the number of particles within the colloidal sol gel.

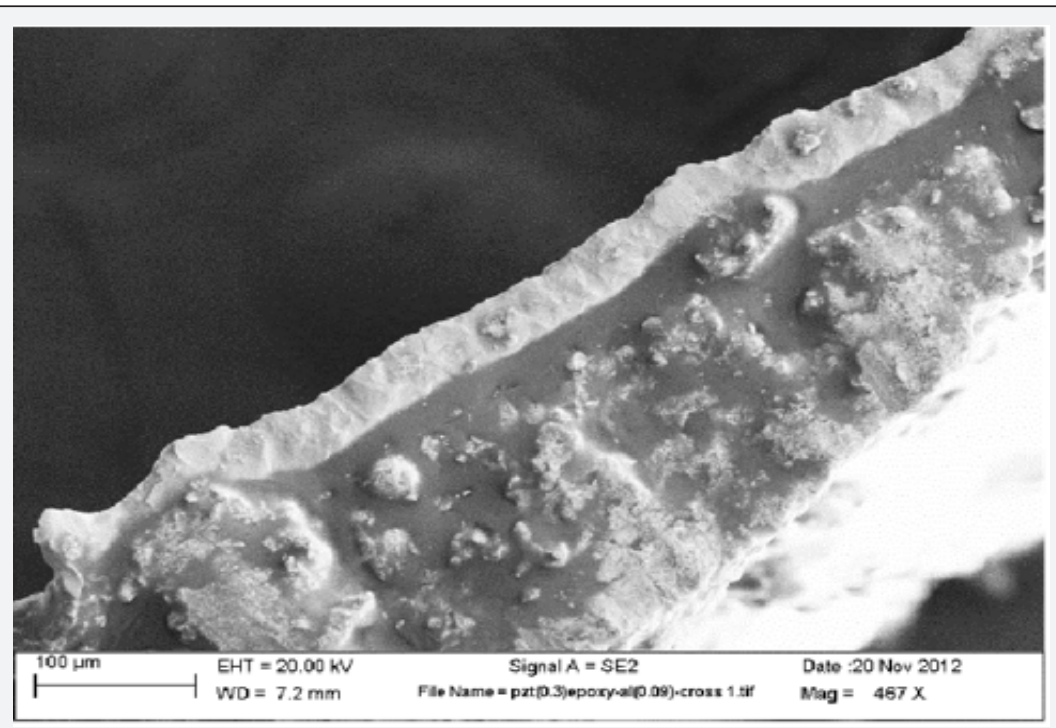

Figure 2: A cross-sectional view of the film thickness (thicknesses of the stainless steel and composite film were 25 and $150 \mu \mathrm{m}$, respectively). The film was comprised of 0.30 and 0.09 volume fractions of PZT and aluminum, respectively. No delamination at the interface between the film and substrate is observed at a magnification of $467 \mathrm{X}$ and $\mathrm{EHT}=20.00 \mathrm{kV}$.

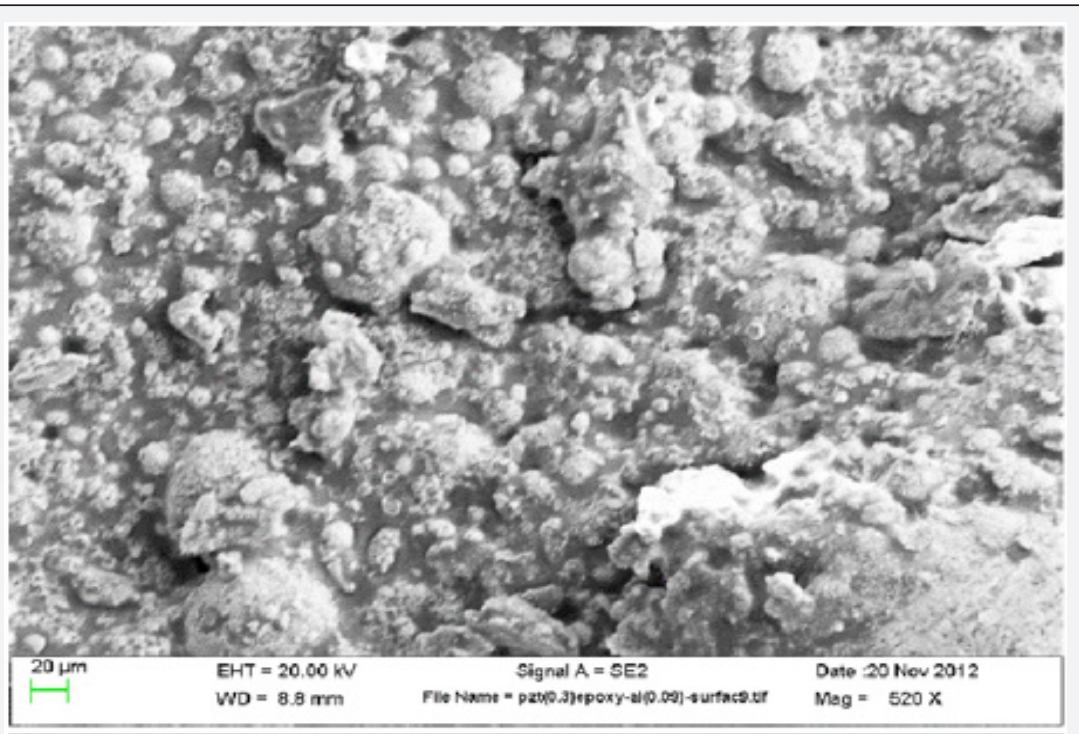

Figure 3: The surface morphology of the composite containing 30\%PZT and $9 \% \mathrm{Al}$ can be seen in the SEM micrographs where the magnification is $520 \mathrm{X}$ and the EHT $=20.00 \mathrm{kV}$. We can see that the formation of PZT clusters or agglomerates occur within the composite. The aluminum particles are distributed around the PZT clusters, which could lead to aluminum-aluminum conductive pathways within the composite. 

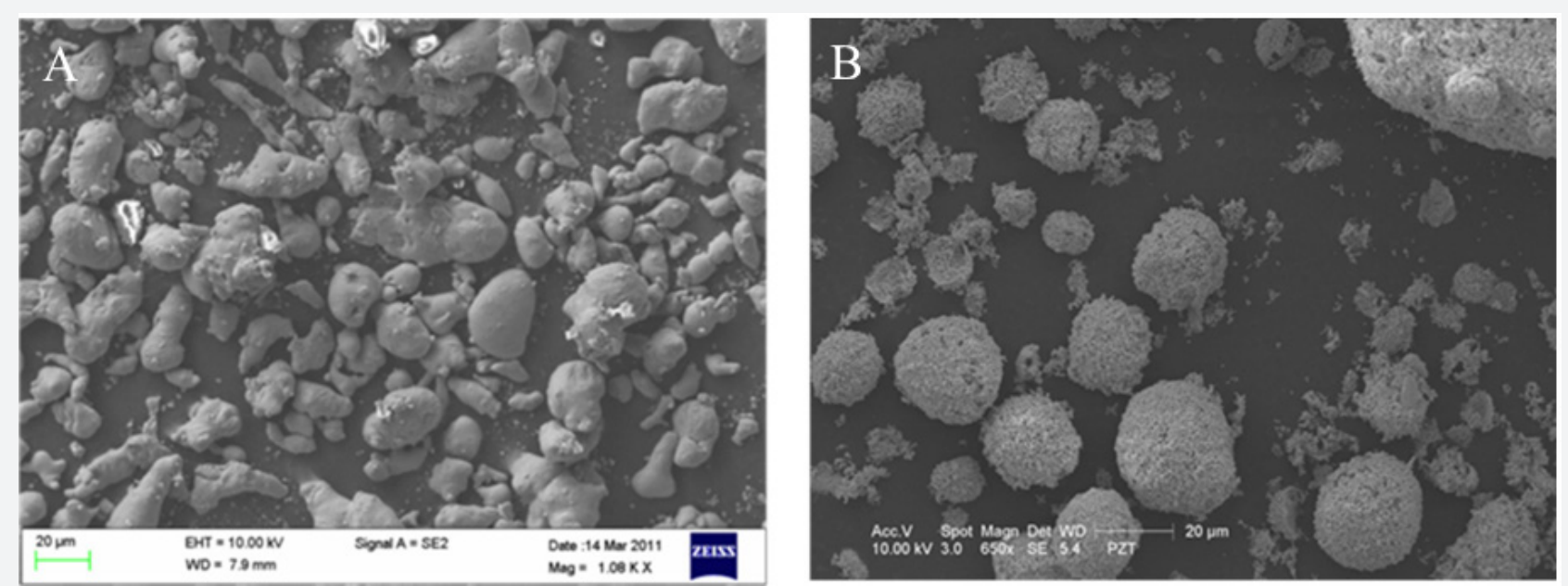

Figure 4: The surface morphologies of the A) micron sized Al inclusions (200mesh) and B) PZT (EC-76 R8658) particles with average particle size $\sim 6-7 \mu \mathrm{m}$. The SEM micrograph of the aluminum is magnified at $1080 \mathrm{X}$ at EHT $=\mathrm{V}$ and the SEM micrograph of the PZT is magnified by $650 \mathrm{X}$ at $10.00 \mathrm{kV}$.

\section{Piezoelectric and dielectric characterization}

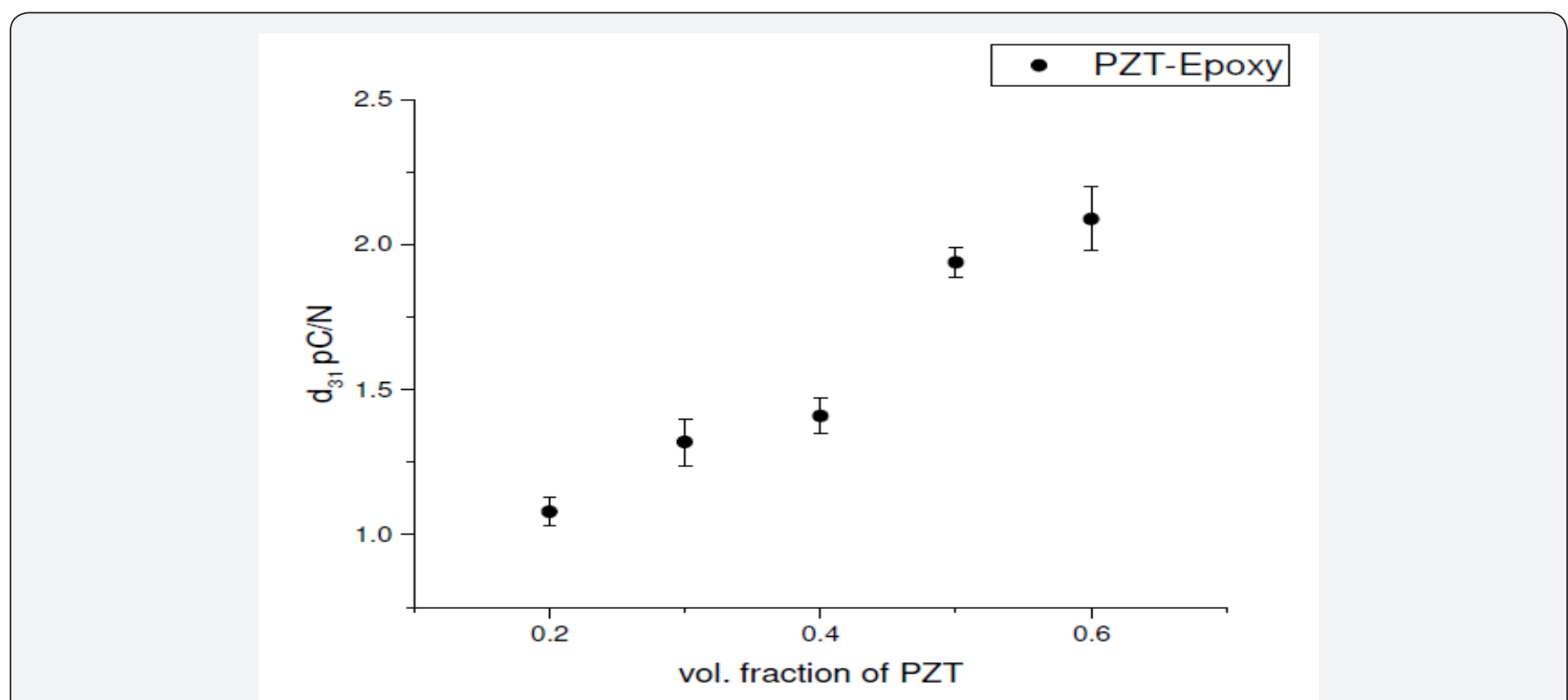

Figure 5: The piezoelectric strain coefficient, $d_{31}$ for the PZT-Epoxy composite that are plotted as a function of volume fraction of PZT. The maximum value is $2.09 \mathrm{pC} / \mathrm{N}$ for $\mathrm{PZT}$ volume fraction of 0.60 . These composites were polarized using the plasma corona discharge method.

In Figure $5 \& 6$, the piezoelectric strain coefficients, $d_{31}$ and $\mathrm{d}_{33}$, for PZT-epoxy film composites are plotted as a function of PZT volume fraction. The films were fabricated in a similar manner as the 0-3-0 films, only they were Corona polarized at $15 \mathrm{kV} / \mathrm{cm}$, instead of Contact Parallel Plated polarized. In Figure $7 \& 8$, the piezoelectric strain coefficients, $\mathrm{d}_{31}$ and $\mathrm{d}_{33}$ of the composites are plotted as a function of $\mathrm{Al}$ (0.0 to 0.17 ) for volume fractions $0.2,0.3$ and 0.4 of PZT, respectively. The PZT-epoxy samples were Corona polarized, but the three phase, 0-3-0 composites were parallelplate contact polarized. As expected, the piezoelectric strain coefficients, $d_{31}$ increased with PZT content and aluminum content up to 0.13 , beyond which there is a steep decline in $d_{31}$ values. The increase in $d_{31}$ values is consistent with many re- searchers such as $[42,49,57]$, who demonstrated increased values of $d_{31}$ with increased PZT content within a piezoelectric polymer composite. A similar trend is expected for $\mathrm{d}_{33}$ values of the composite. However, the magnitude of the $d_{31}$ values is considerably higher than the $d_{33}$ values owing to the higher strain in the direction along the 1-axis as compared to the strain in the 3 -axis. The range of the values of $d_{31}$ and $d_{31}$ are consistent with $[49,58]$ where the active particle size was $<34 \mathrm{~m}$ with a poling voltage equal to $10 \mathrm{kV} / \mathrm{mm}$ at room temperature, which is consistent with the data presented here. The differences in the $\mathrm{d} 31$ and $\mathrm{d}_{31}$ values for the $0-3$ and the $0-3-0$ composites are greater for lower volume fractions of PZT, but the advantage of Corona poling over Contact Parallel plate is evident at lower volume fractions of aluminum. 


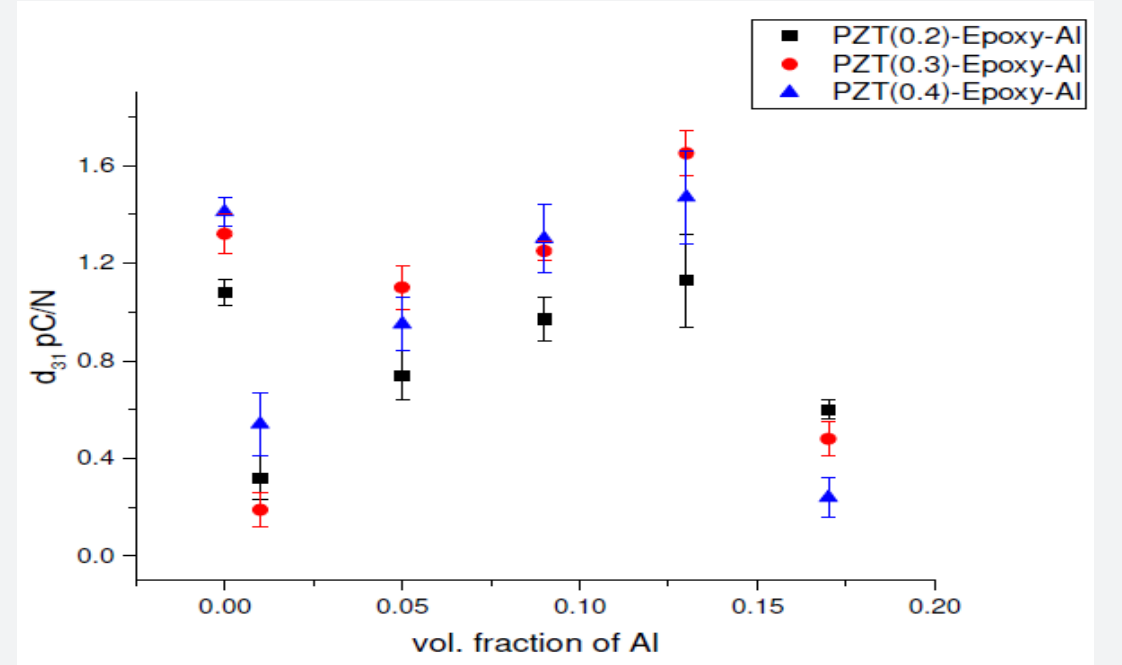

Figure 6: A comparison of piezoelectric strain coefficient $d_{31}$ for the two-phase (PZT-Epoxy) composites plotted as a function of Al volume fraction for PZT at $20 \%, 30 \%$ and $40 \%$. These composites were polarized using the parallel plate polarization method.

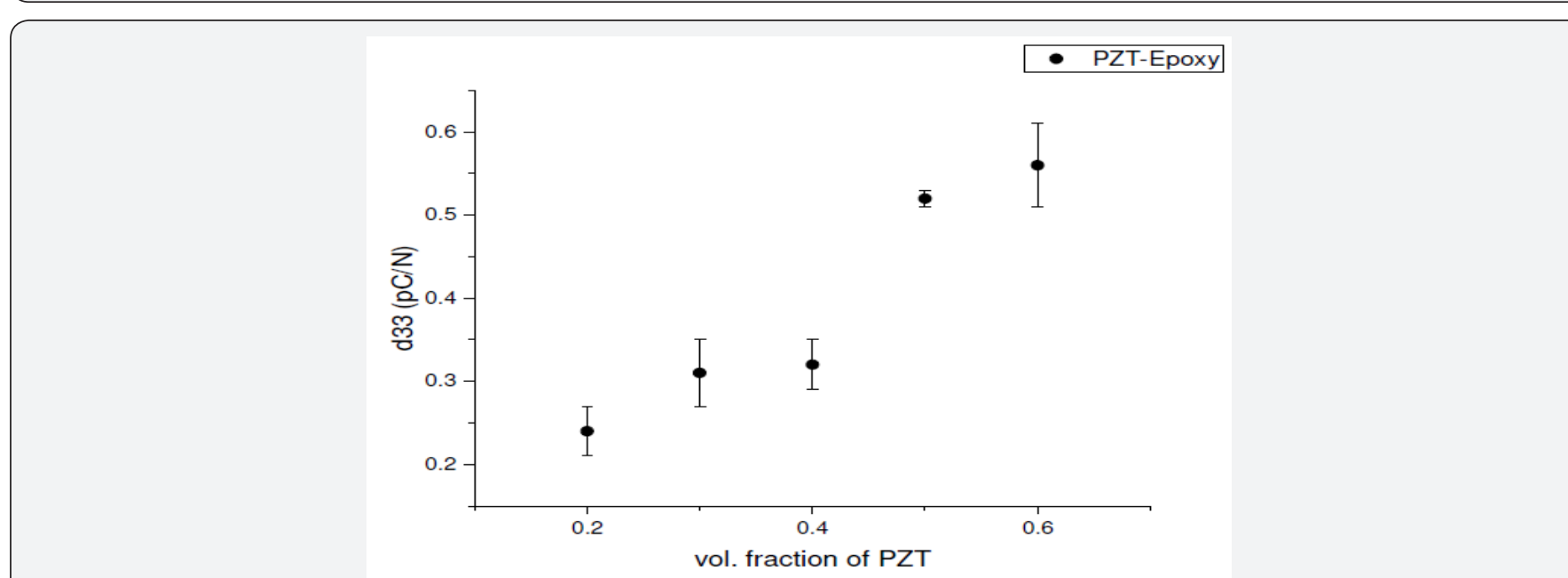

Figure 7: The piezoelectric strain coefficient, $d_{33}$ for the PZT-Epoxy composite that are plotted as a function of volume fraction of PZT. The maximum value is $0.56 \mathrm{pC} / \mathrm{N}$ for $\mathrm{PZT}$ volume fraction of 0.60 . These composites were polarized using the plasma corona discharge method.

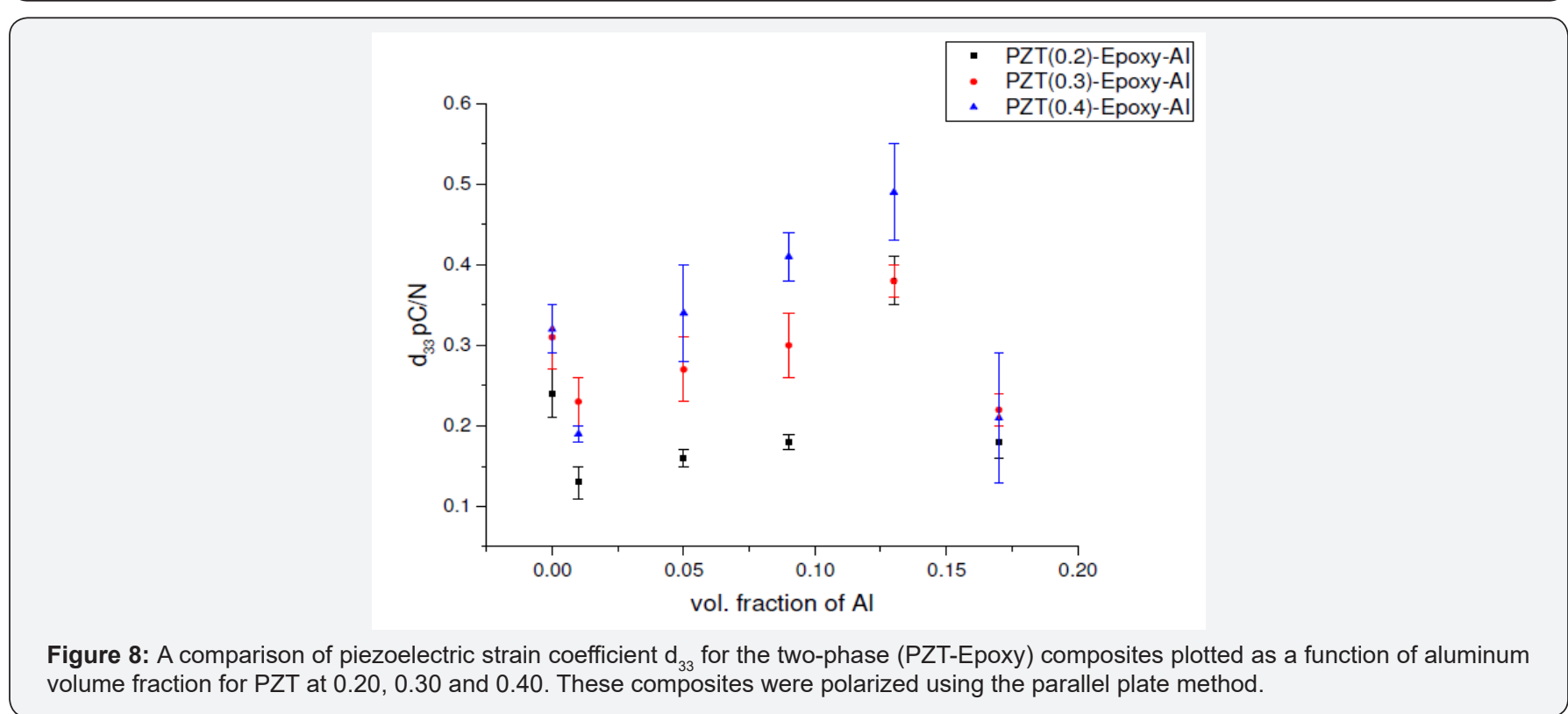


However, at a higher volume fraction of the aluminum (0.13), the $\mathrm{d} 31$ values slightly surpassed those of the PZT-epoxy values for PZT volume fractions of 0.3 and 0.4 .

The capacitance and dielectric constants of the two-phase composites are presented in Figure $9 \& 10$. The capacitance and dielectric constants were found to increase with PZT content, where the maximum value was $\sim 8 \mathrm{pF}$ and $\sim 412$ for the capacitance and permittivity, respectively for a volume fraction of 0.60 for PZT. It was observed that as the PZT con- tent increased, the polarization of the composite enhanced due to PZT's inherent ferroelectric property. Hence, higher overall dielectric constants were observed. It is expected that as the polarization density increases, the ability to store charge in the materials is enhanced as a function of the polarization vector magnitude. The dielectric constants for the three-phase samples are presented (Figure 12). The dielectric constants for all samples increase with volume fraction of PZT and aluminum as was similar to the observations of [59-61]. All samples containing the aluminum filler had higher dielectric constants than their two-phase counterparts. The three-phase system with aluminum particles closely resembled a percolative system [62-68].

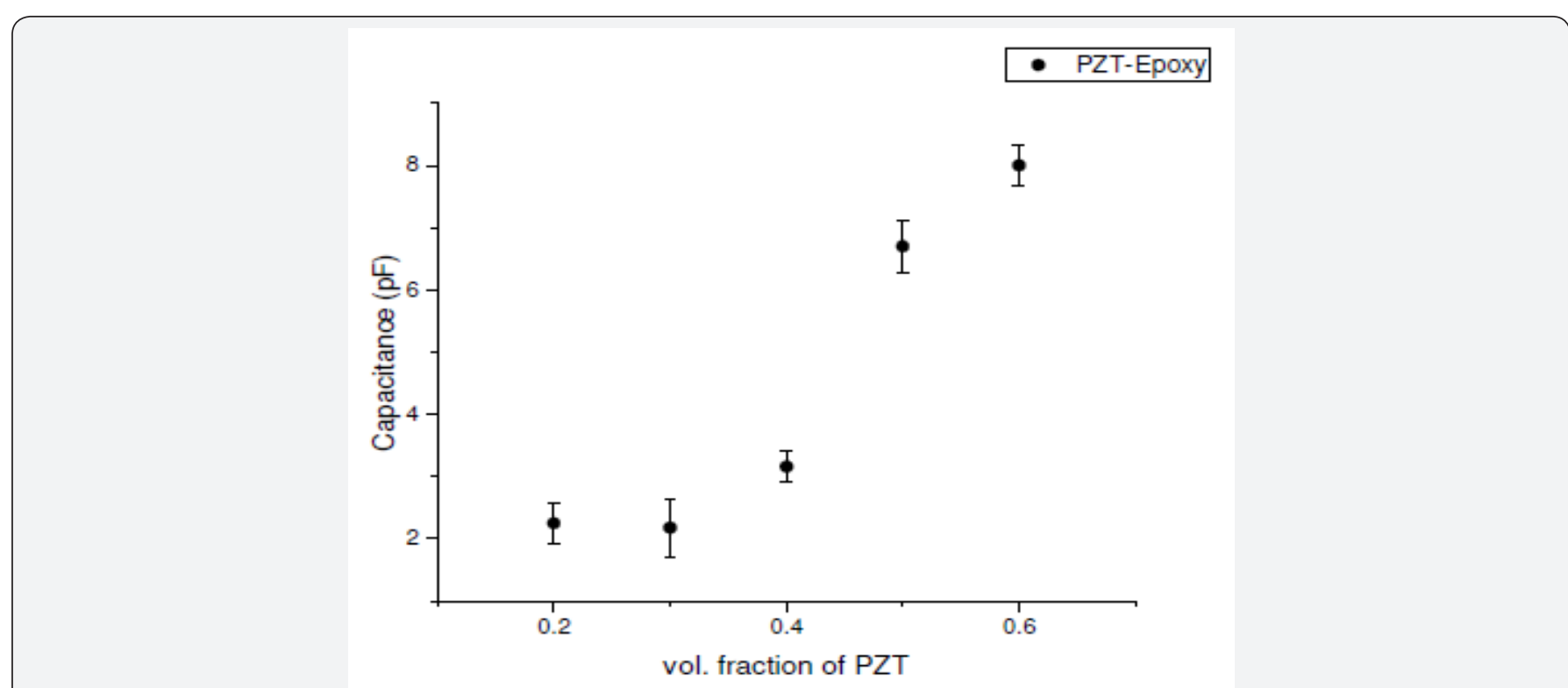

Figure 9: The capacitance for the PZT-epoxy composite that are plotted as a function of PZT volume fraction. The maximum value is $8 \mathrm{pF}$ and occurs at 0.60 volume fraction of PZT, which is a low value. However, the low value is due to the poor dielectric and electrically insulative properties of the epoxy used. These composites were polarized using the plasma corona discharge method.

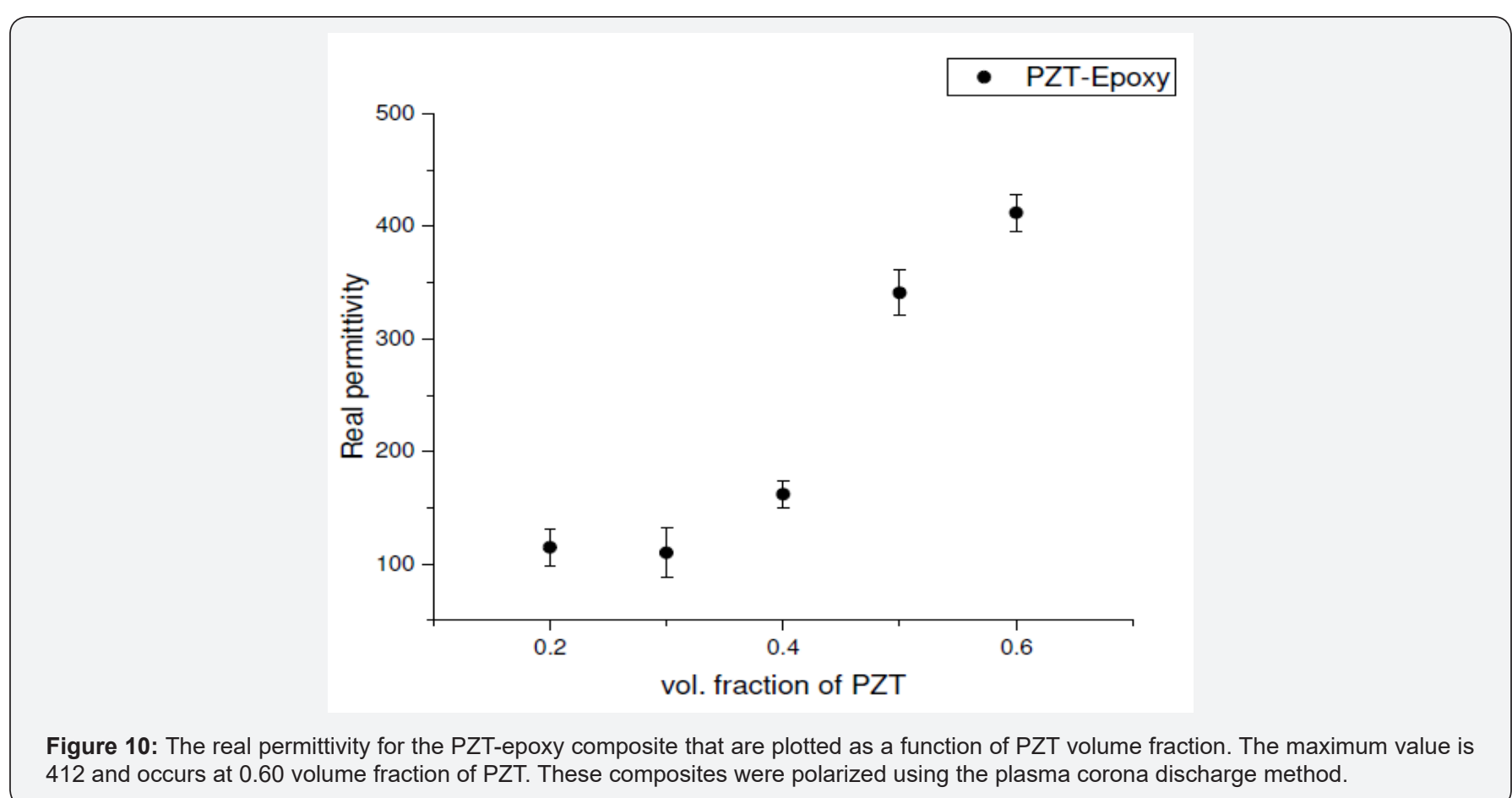




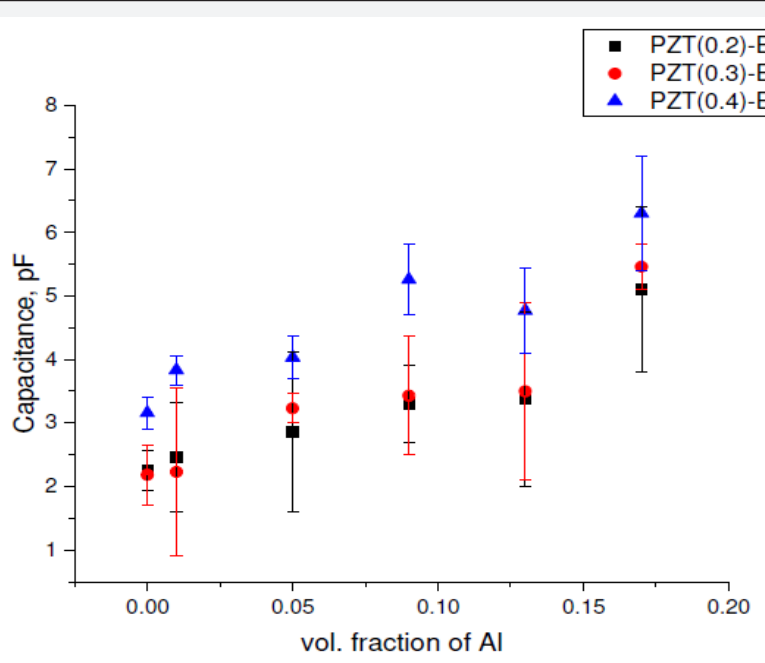

Figure 11: A comparison of capacitance values for the two-phase (PZT-Epoxy) composites plotted as a function of aluminum volume fraction for PZT at $0.20,0.30$ and 0.40 . The three phase composites were polarized using the parallel plate method, while the two-phase composites were polarized using the plasma corona discharge method. The capacitance of the three phase composites are shown to have higher.

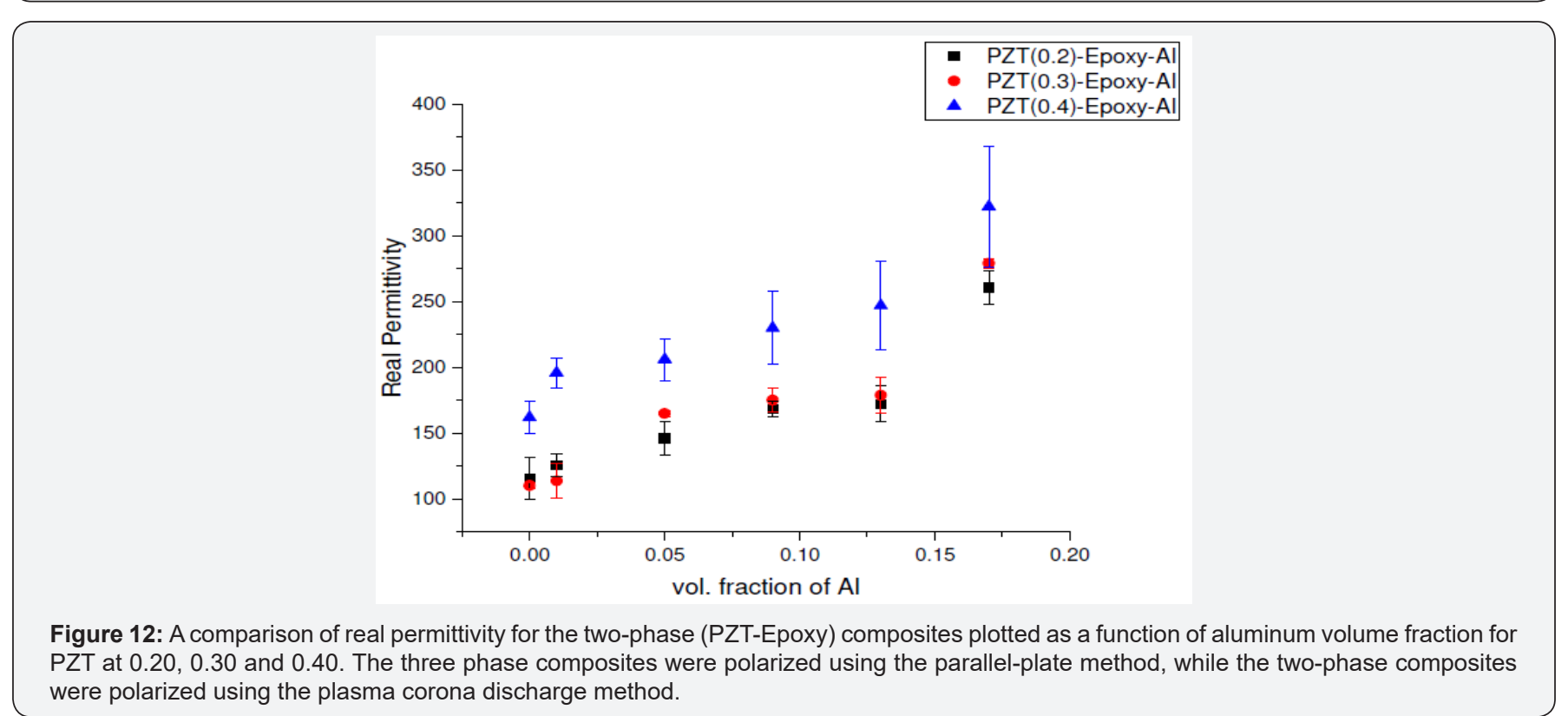

This interfacial polarization or the so-called Maxwell-Wagner effect is responsible for the enhancement of the dielectric constant $[63,64]$. This increase in dielectric constant corresponds to an increase in volume fraction of aluminum particles and culminates at a critical value, known as the percolation threshold. Beyond this critical value the system begins to conduct electricity due to either (i) electron tunneling or electron hopping effect and/or (ii) the presence of conductive pathways, which geometrically align. Beyond this percolation range, the composite thick films cease to be a dielectric and become electrically conductive [63, 64]. The dielectric constant values increased near percolation threshold due to the presence of micro-capacitor networks. These networks are formed by neighboring conductive filler particles [65-68] that sandwich PZT particles that are insulated by the polymer matrix. Once the micro capacitor networks begin to accrue in number, they contribute to an overall increase in capacitance $[69,70]$ of the overall sample. The creation of these networks results in an increase in the local electric field when the conductive fillers are close together near percolation which pro- motes migration and accumulation of charge carriers at the interfaces between the aluminum particles and the insulating polymer matrix. These generated charges are then accumulated at the interface and once the conductive particles appear too close to one another they are relaxed by tunneling or ohmic conduction [63, 65-68]. The maximum value of dielectric constant was observed for samples that contained $0.40 \mathrm{PZT}$ and 0.17 aluminum.

\section{Analysis of piezoelectric effect as a function of top elec- trode}

Gold and silver top electrodes were applied to PZT (0.3)-Epoxy $(0.05)$ samples to evaluate its influence on the electromechanical 
properties of the composite. Colloidal silver solution was applied as the top electrode with $5 \mu \mathrm{m}$ thickness (Figure 13) and $400 \mathrm{~nm}$ gold was sputtered on the sample using a sputtering machine (Figure 14).

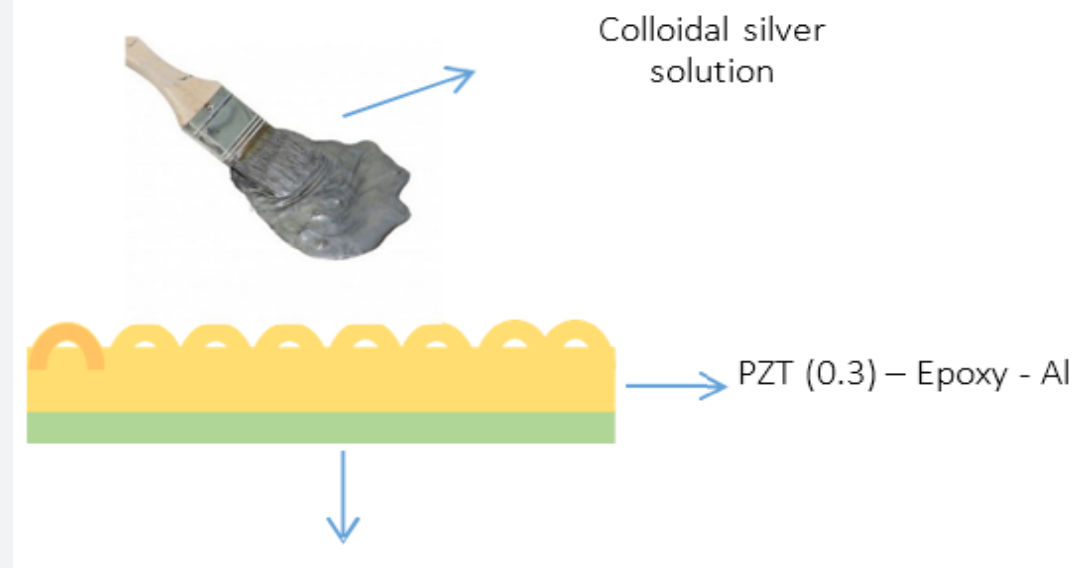

\section{Stainless steel substrate}

Figure 13: A schematic diagram of the application of the $5 \mu \mathrm{m}$ thick colloidal silver electrode onto the surface of the film.

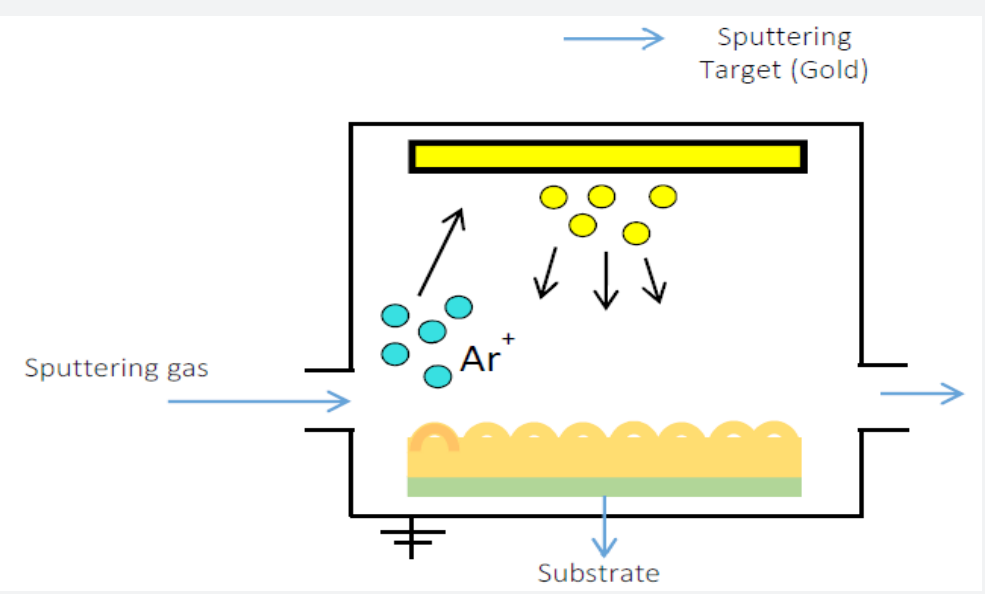

Figure 14: A schematic diagram describing the sputtering process of $400 \mathrm{~nm}$ gold layer onto the thick film. The molecules of the sputtering gas (argon), strike the gold target thereby releasing gold molecules onto the surface of the film.

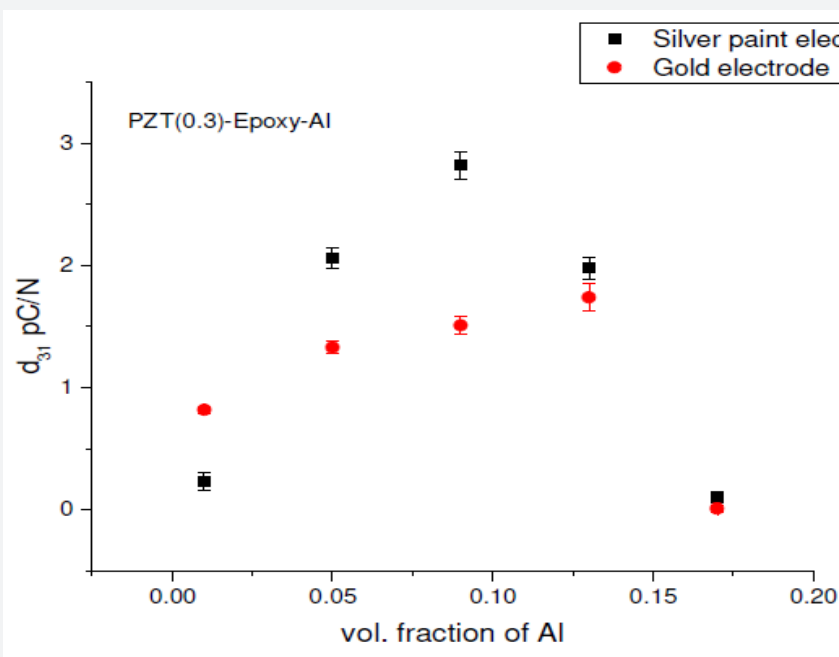

Figure 15: A Comparison of piezoelectric strain coefficient $d_{31}$ for samples containing 0.30 PZT volume fraction and $0.05 \mathrm{Al}$ volume fraction with silver and gold electrodes. 


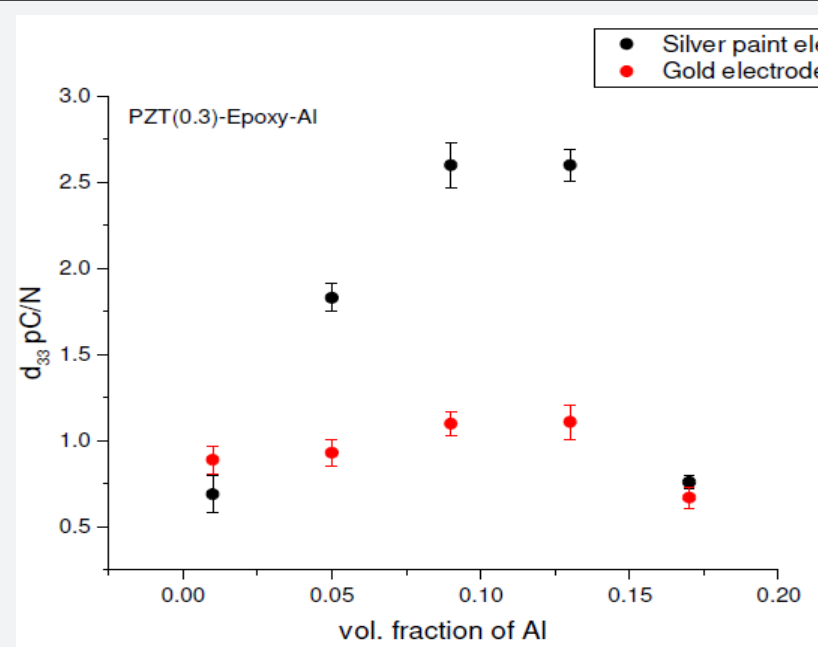

Figure 16: A Comparison of piezoelectric strain coefficient $d_{33}$ for samples containing $30 \%$ PZT volume fraction and 0.05 Al volume fraction with silver and gold electrodes.

The electron transport properties at the interface of the composite thick film surface and the device electrode are influenced by the surface characteristics, such as the surface morphology of the thick films, the contact resistance and the total number of contact points connecting the thick film surface to the surface of the device electrode [71-73]. To draw a comparison between different top electrodes, the thick films were deposited with gold $(\mathrm{Au})$ and silver $(\mathrm{Ag})$ electrodes. The electrical resistivity and conductivity values are different for both materials. The variation in the piezoelectric strain coefficients $d_{33}$ and $d_{31}$ of the thick film are shown in Figure $15 \& 16$. The values are enhanced by the addition of the metallic electrodes below the percolation threshold. This improvement in the $\mathrm{d}_{33}$ and $\mathrm{d}_{31}$ values is due to the decrease in the contact resistance and increase in the mobility of electrons at the interface between the film surface and the electrode due to the presence of the metallic layer [72]. We can see a maximum $d_{31}$ and $d_{33}$ values for the samples with silver electrode are $2 \mathrm{pC} / \mathrm{N}$ and $2.5 \mathrm{pC} / \mathrm{N}$, respectively occur at $\sim 13 \% \mathrm{Al}$. These values are higher than that of gold, $\mathrm{d}_{31}$ and $\mathrm{d}_{33}$ are $\sim 1.8 \mathrm{pC} / \mathrm{N}$ and $\sim 1.2 \mathrm{pC} / \mathrm{N}$, respectively because of the decreased electrical resistivity of silver (Ag $\sim 0.0095510-8 \Omega \mathrm{m}$ and $\mathrm{Au} \sim 0.0502$ 10-8 $\Omega \mathrm{m})$ [74].

The capacitance values are enhanced by the addition of the top electrode. The top electrodes were applied to samples containing a PZT volume fraction equal to 0.3 and aluminum volume fraction equal to 0.05 . The capacitance for of the samples with the gold electrodes were $\sim 43 \mathrm{pF}, \sim 42.8 \mathrm{pF}$ for the silver electrode and $\sim 3.5 \mathrm{pF}$ when no electrode was applied. The enhancement of the capacitance could be due to several factors such as electron tunneling due to an increase in the intensity of local electric field [63]. Also, the conductive layer reduces the losses due to metal insulator transition and other interface defects as compared to the compo- site without a conductive layer [72].

\section{Effect of aging of samples}

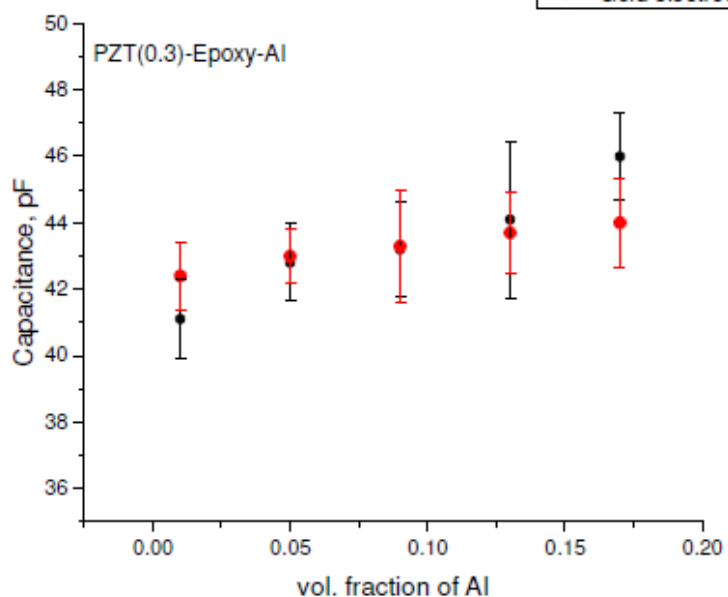

Figure 17: A Comparison of capacitance for samples containing 0.30 PZT volume fraction and $0.05 \mathrm{Al}$ volume fraction with silver and gold electrodes. 
The composite properties were also recorded as a function of time: 1, 5 and 1027 days of poling, to study the effect of aging on the electromechanical properties of the composite. The values measured after five days were slightly lower than the values recorded after one day as indicated in Figures $17 \& 18$ through 21 . This happened because the samples reached remnant polarization gradually over time, and thus attained lower $\mathrm{d}_{33}$ and $d_{31}$ values as some of the dipoles that were forced to return to their original position. The samples were measured again, 1027 days after poling, the $d_{31}$ and $d_{33}$ values reduced only slightly $(0.105$ 0.235 less compared $d_{33}$ of 5 days after poling), however they did observe a similar trend in values varying with aluminum volume fraction, as shown in Figure 20 \& 21.

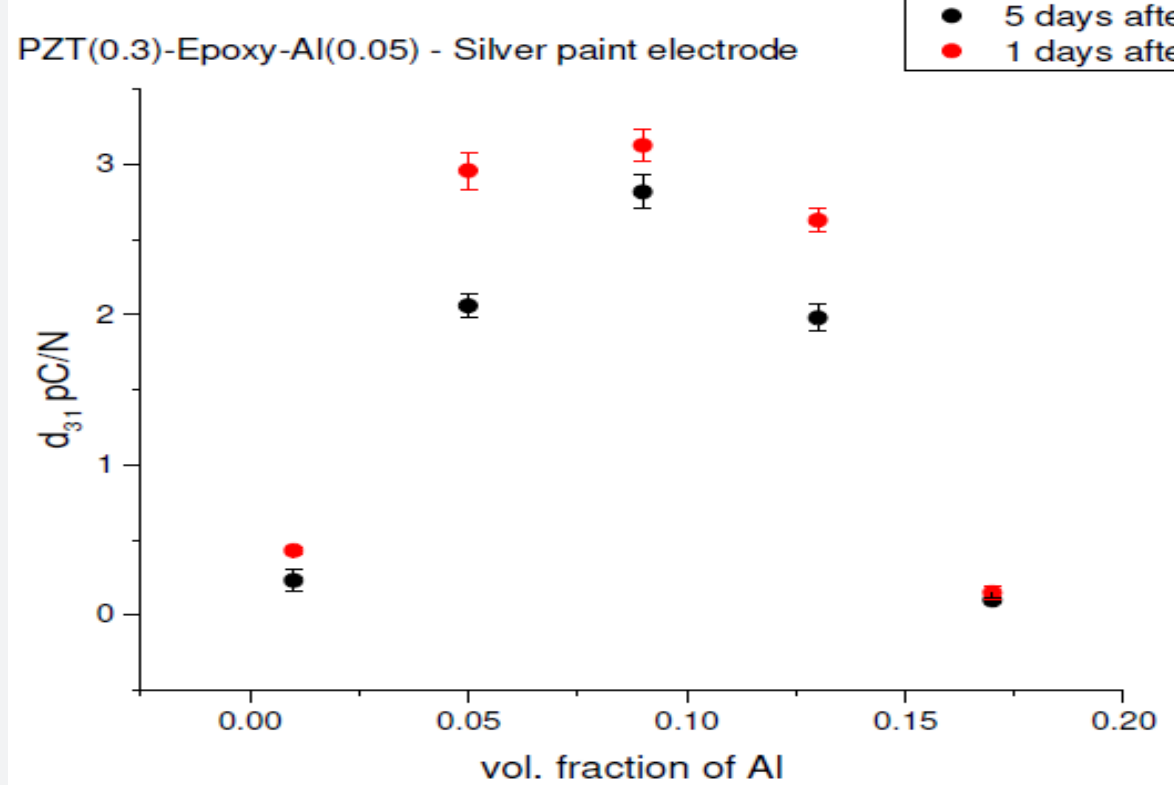

Figure 18: A comparison of the piezoelectric strain coefficient, $d_{31}$ as a function of aging time i.e. time elapsed since poling the sample and recording the measurements, in this case a) one day and b) five days, for samples with 0.30 PZT and varying Al volume fraction with silver electrode.

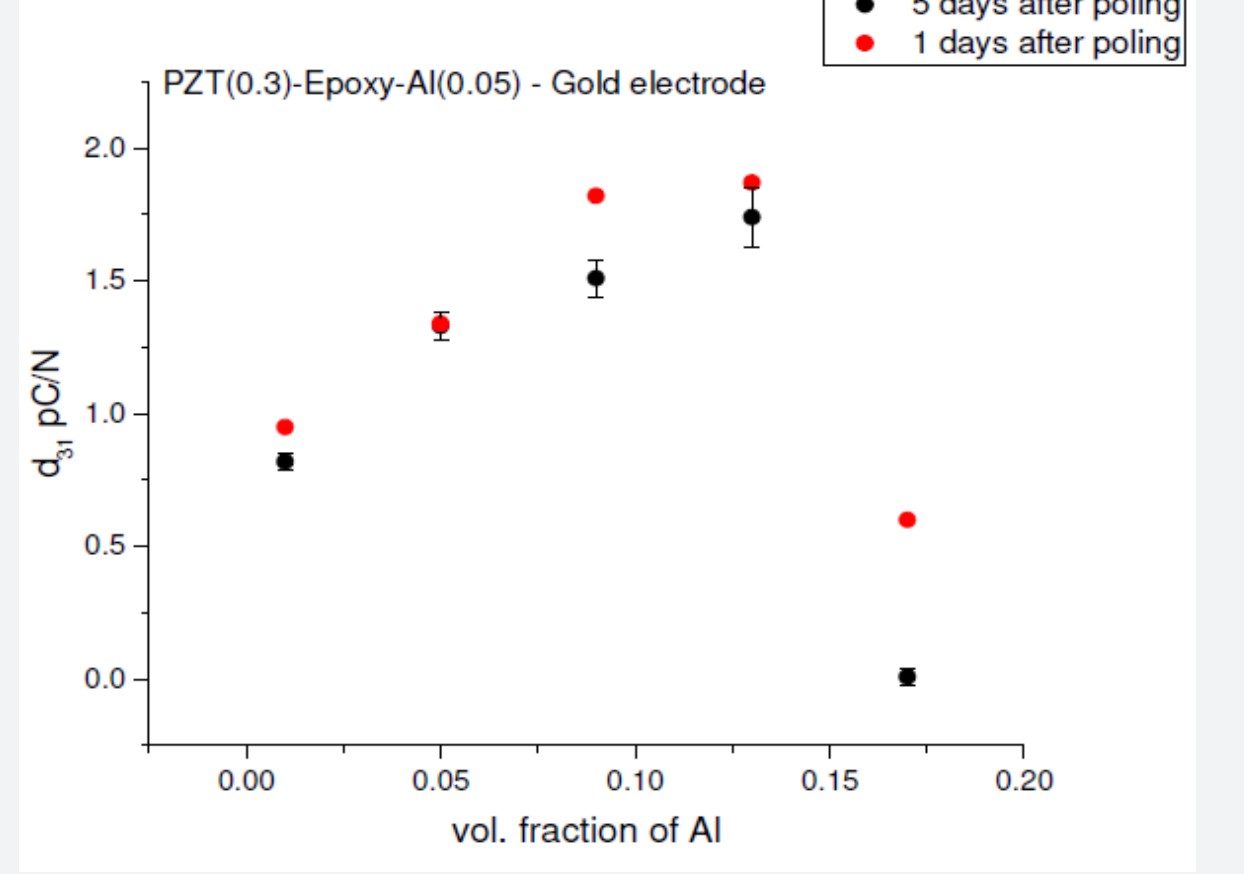

Figure 19: A comparison of the piezoelectric strain coefficient, $d_{31}$ as a function of aging time i.e. time elapsed since poling the sample and recording the measurements, in this case a) one day and b) five days, for samples with $0.30 \mathrm{PZT}$ and $0.05 \mathrm{Al}$ volume fraction with gold electrode. 


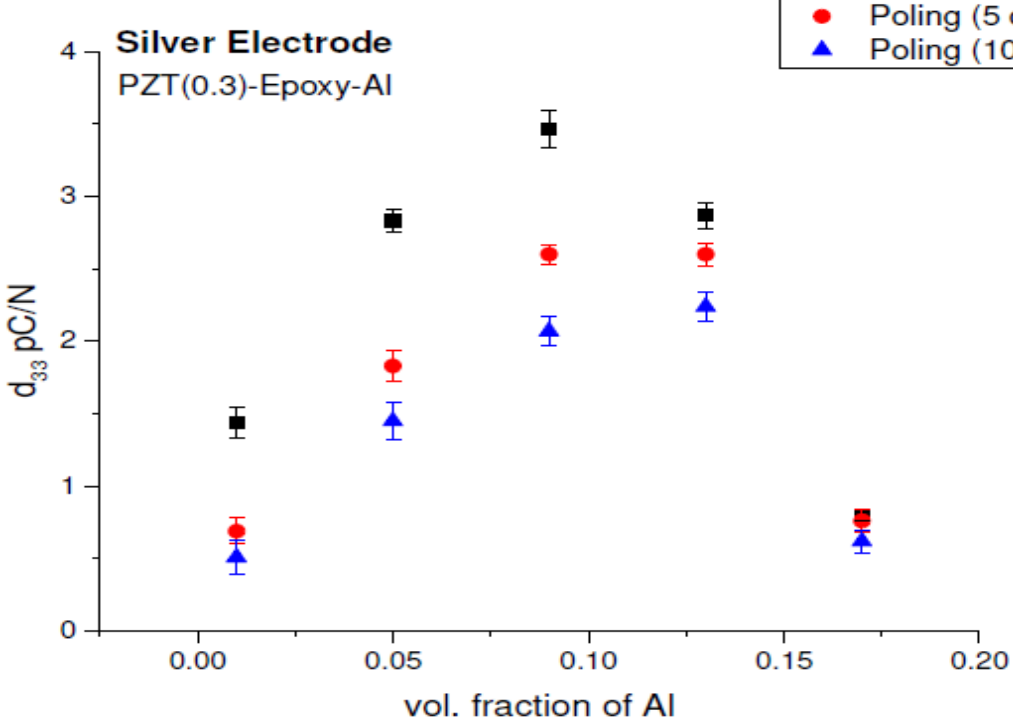

Figure 20: A comparison of the piezoelectric strain coefficient, $d_{33}$ as a function of aging time i.e. time elapsed since poling the sample and recording the measurements, in this case a) one day and b) five days, for samples with 0.30 PZT and 0.05 Al volume fraction with silver electrode.

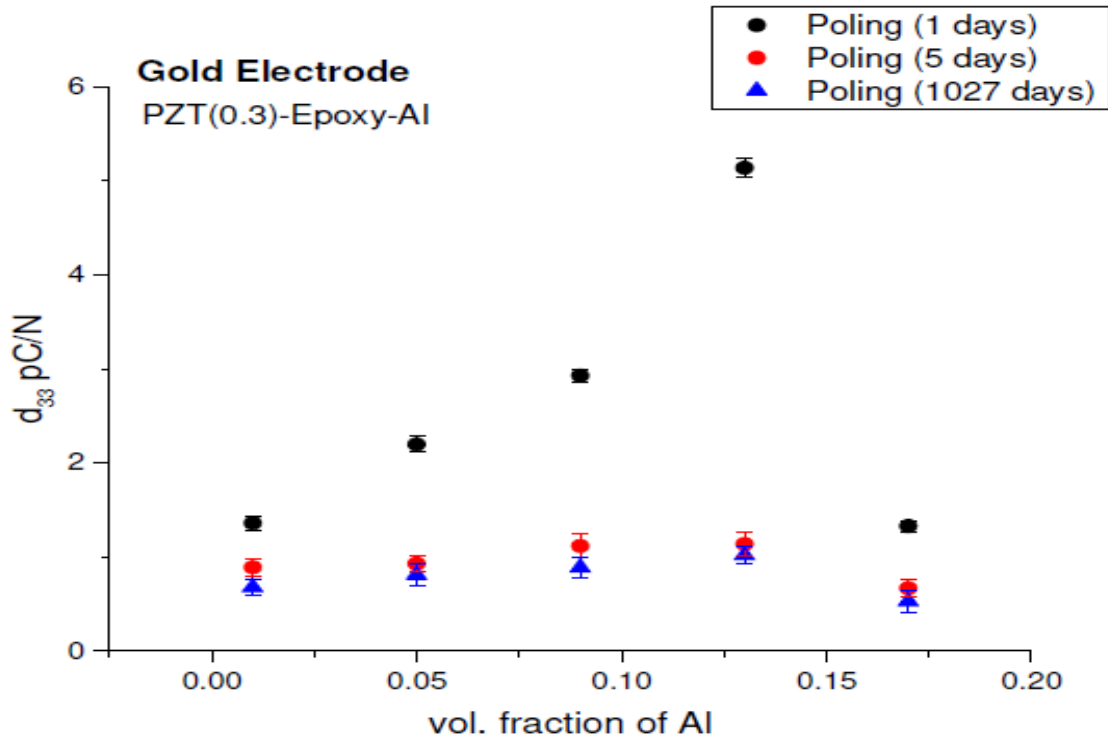

Figure 21: A comparison of the piezoelectric strain coefficient, $d_{33}$ as a function of aging time i.e. time elapsed since poling the sample and recording the measurements, in this case a) one day and b) five days, for samples with $0.30 \mathrm{PZT}$ and $0.05 \mathrm{Al}$ volume fraction gold electrode.

\section{Conclusion}

Three-phase piezoelectric PZT-epoxy-Al thick film composites were fabricated and poled using parallel-plate contact poling method. The volume fractions of PZT and Al were varied from 0.2 to 0.4 and 0.0 to 0.17 respectively. The piezoelectric strain coefficient, $\mathrm{d}_{33}$ and $\mathrm{d}_{31}$ and the dielectric constant increased with PZT and Al volume content. Furthermore, the piezo- electric strain coefficients, longitudinal and axial, increased with Al volume fraction culminating at 0.13 , beyond which the values began to drop. Two different top electrodes were applied to the samples, gold and silver and their values were compared. Silver proved to result in better overall properties due to reduced electrical resistivity at the interface. An aging study was also carried out to measure the piezoelectric strain coefficients between 1,5 and 1027 days. The results showed that the values gradually dropped over time, falling quickly between 1 and 5 days, and more gradually between 5 and 1027 days.

\section{Acknowledgement}

This material is based upon work supported by the National Science Foundation under Grant Numbers: EEC1659818, 
EEC1263250 and EEC1407266. In addition, we would like to acknowledge support from the New Jersey Space grant Consortium.

\section{References}

1. Sundar U, Cook-Chennault KA, S Banerjee, Refour E (2016) Dielectric and piezoelectric properties of percolative three-phase piezoelectric polymer composites. Journal of Vacuum Science \& Technology B 34(4).

2. SK Bhattacharya, RR Tummala (2002) Epoxy nanocomposite capacitors for application as MCM-L compatible integral passives. Journal of Electronic Packaging 124(1): 1-6.

3. SK Bhattacharya, RR Tummala (2000) Next generation integral passives: materials, processes, and integration of resistors and capacitors on PWB substrates. Journal of Materials Science- Materials in Electronics 11(3): 253-268.

4. P Muralt (2000) PZT thin films for microsensors and actuators: Where do we stand? Ultrasonics, Ferroelectrics, and Frequency Control. IEEE Transactions 47(4): 903-915.

5. KA Cook-Chennault, N Thambi, AM Sastry (2008) Powering MEMS portable devices - a review of non-regenerative and regenerative power supply systems with special emphasis on piezoelectric energy harvesting systems. Smart Materials and Structures 17(4): 33.

6. KA Cook-Chennault, N Thambi, MA Bitetto, E Hameyie (2008) Piezoelectric Energy Harvesting: A Green and Clean Alternative for Sustained Power Production. Bulletin of Science Technology \& Society 28(6): 496-509.

7. Y Zhen, JF Li (2008) Preparation and electrical properties of finescale 1-3 lead zirconic titanate/epoxy composite thick films for highfrequency ultrasonic transducers. Journal of Applied Physics 103(8): 4119.

8. J Nunes-Pereira, Manab Kundu, Attila Gören, Maria Manuela Silva, Carlos M Costa, et al. (2016) Optimization of filler type within poly (vinylidene fluoride-co- trifluoroethylene) composite separator membranes for improved lithium-ion battery performance. Composites Part B-Engineering 96: 94-102.

9. J Nunes-Pereira, CM Costa, RE Sousa, AV Machado, MM Silva, et al (2014) Li-ion battery separator membranes based on barium titanate and poly (vinylidene fluoride-co- trifluoroethylene): Filler size and concentration effects. Electrochimica Acta 117: 276- 284.

10.ZY Hu, LP Li, JJ Zhou, L Li (2015) Preparation and Performance of Inorganic Composite Separators for Lithium-ion Battery. Acta Polymerica Sinica 11: 1288-1293.

11. McClarren B, Olabisi R (2018) Strain and Vibration in Mesenchymal Stem Cells. International Journal of Biomaterials 2018: 13

12. Cook KA, Albano F, Nevius PE, Sastry AM (2006) POWER (power optimization for wireless energy requirements): A MATLAB based algorithm for design of hybrid energy systems. Journal of Power Sources 159(1): 758-780.

13. Krupanidhi S, Maffei N, Sayer M, El-Assal K (1983) RF planar magnetron sputtering and characterization of ferroelectric $\mathrm{Pb}(\mathrm{Zr}, \mathrm{Ti}) 03$ films Journal of Applied Physics 54(11). 6601-6609.

14. Okuyama M, Usuki T, Hamakawa Y, Nakagawa T (1980) Epitaxial growth of ferroelectric PLZT thin film and their optical properties. Applied physics 21(4): 339-343.

15. Castellano R, Feinstein L (1979) Ion-beam deposition of thin films of ferroelectric lead zirconate titanate (PZT). Journal of Applied Physics 50(6): 4406-4411.

16. Sreenivas K, Sayer M, Garrett P (1989) Properties of DC magnetronsputtered lead zirconate titanate thin films. Thin Solid Films 172(2): 251-267.
17. Kwak B, Boyd E, Erbil A (1988) Metalorganic chemical vapor deposition of $\mathrm{PbTiO}_{3}$ thin films. Applied physics letters 53(18): 1702-1704.

18. Kojima M, Okuyama M, Nakagawa T, Hamakawa Y (1983) Chemical Vapor Deposition of $\mathrm{PbTiO}_{3}$ Thin Film. Japanese Journal of Applied Physics 22(S2): 14

19. Okada M, Takai S, Amemiya M, Tominaga K (1989) Preparation of c-axis-oriented PbTiO3 thin films by MOCVD under reduced pressure. Japanese Journal of Applied Physics 28(6): 1030.

20. Budd KD, Key S, Payne D (1985) Sol-gel processing of $\mathrm{PbTiO}_{3}, \mathrm{PbZr} \mathrm{O}_{3}$ PZT and PLZT thin films. In Br Ceram Proc 36:107-121.

21. Dey S, Budd KD, Payne DA (1987) Thin-film ferroelectrics of PZT of sol-gel processing. IEEE transactions on ultrasonics, ferroelectrics, and frequency control 35(1): 80-81.

22. Spierings G, Ulenaers M, Kampschöer G, Van Hal H, Larsen P (1991) Preparation and ferroelectric properties of $\mathrm{PbZr}_{0.53} \mathrm{Ti}_{0.47} \mathrm{O}_{3}$ thin films by spin coating and metalorganic decomposition. Journal of applied physics 70(4): 2290-2298.

23. Tuttle B, Headley TJ, Bunker BC, Schwartz RW (1992) Microstructural evolution of $\mathrm{Pb}(\mathrm{Zr}, \mathrm{Ti}) \mathrm{O}_{3}$ thin films prepared by hybrid metalloorganic decomposition. Journal of materials research 7(7): 1876-1882.

24. Otsubo S, Maeda T, Minamikawa T, Yonezawa Y, Morimoto A, et al. (1990) Preparation of $\mathrm{Pb}\left(\mathrm{Zn}_{0.52} \mathrm{Ti}_{0.48}\right) \mathrm{O}_{3}$ films by laser ablation. Japanese journal of applied physics 29(1): L133.

25. Buhay H, Sinharoy S, Kasner W, Francombe M (1991) Pulsed laser deposition and ferroelectric characterization of bismuth titanate films. Applied physics letters 58(14): 1470-1472.

26. Roy D, Krupanidhi S, Dougherty J (1991) Excimer laser ablated lead zirconate titanate thin films. Journal of applied physics 69(11): 79307932.

27. Corkovic S, Whatmore R, Zhang Q (2007) Sol-gel fabrication of PZT thick films for MEMS. Integrated Ferroelectrics 88(1): 93-102.

28. Li K, Chan HK, Lee K, Choy C (2000) Preparation of thick PZT films on stainless steel substrates. Integrated Ferroelectrics 30(1-4): 253-260.

29. Banerjee S, Cook-Chennault KA (2011) Influence of Al Particle Size and Lead Zirconate Titanate (PZT) Volume Fraction on the Dielectric Properties of PZT-Epoxy-Aluminum Composites. Journal of Engineering Materials and Technology-Transactions of the Asme 133(4).

30. Banerjee S, Cook-Chennault KA (2011) An Analytical Model for the Effective Dielectric Constant of a 0-3-0 Composite. Journal of Engineering Materials and Technology-Transactions of the Asme 133(4).

31. Banerjee S, Cook-Chennault KA (2012) An investigation into the influence of electrically conductive particle size on electromechanical coupling and effective dielectric strain coefficients in three phase composite piezoelectric polymers," Composites Part a-Applied Science and Manufacturing 43(9): 1612-1619.

32. Banerjee S, Du W, Wang L, Cook-Chennault KA (2013) Fabrication of dome-shaped PZT-epoxy actuator using modified solvent and spin coating technique. Journal of Electroceramics 31(1-2): 148-158.

33. Cook-Chennault KA, Banerjee S, Asme (2012) An analytical model for the effective dielectric constant of a 0-3-0 composite. In: Proceedings of the Asme International Mechanical Engineering Congress and Exposition 2010. 12: pp. 65-70.

34. Banerjee S, Cook-Chennault KA (2014) Influence of aluminium inclusions on dielectric properties of three-phase PZT-cementaluminium composites. Advances in Cement Research 26(2): 63-76

35. Banerjee S, Torres J, Cook-Chennault KA (2015) Piezoelectric and dielectric properties of PZT- cement-aluminum nano-composites. Ceramics International 41(1): 819-833. 
36. Nguyen TT, Mai Phan TT, Chu NC, Luu VB, Nguyen XH (2016) Elaboration and Dielectric Property of Modified PZT/Epoxy Nanocomposites. Polymer Composites 37(2): 455-461.

37. Chao F, Liang GZ, Kong WF, Zhang X (2008) Study of dielectric property on BaTi03/BADCy composite. Materials Chemistry and Physics 108(23): 306-311.

38. Malmonge JA, Malmonge LF, Fuzari GC, Malmonge SM, Sakamoto WK (2009) Piezo and Dielectric Properties of PHB-PZT Composite. Polymer Composites 30(9): 1333-1337.

39. Hanner K, Safari A, Newnham R, Runt J (1989) Thin film 0-3 polymer/ piezoelectric ceramic composites: Piezoelectric paints. Ferroelectrics 100(1): 255-260.

40. Newnham R, Skinner D, Cross L (1978) Connectivity and piezoelectric pyroelectric composites. Materials Research Bulletin 13(5): 525-536.

41. Newnham R, Safari A, Giniewicz J, Fox B (1984) Composite piezoelectric sensors. Ferroelectrics 60(1): 15-21.

42. Banno H, Ogura K (1991) Piezoelectric properties of 0-3 composite of polymer and ceramic powder mixture of PZT and PbTiO3. Japanese journal of applied physics 30(9B): 2247.

43. Sain PK, Goyal RK, Bhargava AK, Prasad Y (2014) Thermal and Dielectric Behavior of Flexible Polycarbonate/Lead Zirconate Titanate Composite System. Journal of Applied Polymer Science 131(4).

44. Banerjee S, Cook-Chennault KA, Du W, Sundar U, Halim H, et al. (2016) Piezoelectric and dielectric characterization of corona and contact poled PZT-epoxy-MWCNT bulk composites. Smart Materials and Structures 25(11).

45. Banerjee S, Kappera R, Cook-Chennault KA, Chhowalla M (2013) Multi-walled carbon- nanotube based flexible piezoelectric films with graphene monolayers. Energy and Environment Focus 2(3): 195202(8).

46. KA Cook-Chennault, N Thambi, MA Bitetto, Hameyie E B (2008) Piezoelectric Energy Harvesting: A Green and Clean Alternative for Sustained Power Production. Bulletin of Science Technology \& Society 28(6): 496-509.

47. K A Cook-Chennault, D Cosaboon, D Eigbe, B Pitcavage, M Whitzer, et al. (2012) Enhanced Output Voltage and Power From Conductive Inclusions In A 0-3-0 Piezoelectric Composite. Proceedings of the Asme International Mechanical Engineering Congress and Exposition 12: 61-64.

48. (1949) Transducer and method of making the same ed: Google Patents.

49. D Corker, Q Zhang, R Whatmore, C Perrin (2002) PZT 'composite'ferroelectric thick films. Journal of the European Ceramic Society 22(3): 383-390.

50. A Kholkin, V Yarmarkin, A Wu, M Avdeev, P Vilarinho, et al. (2001) PZTbased piezoelectric composites via a modified sol-gel route. Journal of the European Ceramic Society 21(10-11): 1535-1538.

51. D Waller, A Safari (1988) Corona poling of PZT ceramics and flexible piezoelectric composites. Ferroelectrics 87(1): 189-195.

52. Z Wang, W Zhu, C Zhao, O K Tan (2003) Dense PZT thick films derived from sol-gel based nanocomposite process. Materials Science and Engineering: B 99(1): 56-62.

53. S Banerjee, K Cook-Chennault (2011) Influence of Al particle size and lead zirconate titanate (PZT) volume fraction on the dielectric properties of PZT-epoxy-aluminum composites. Journal of Engineering Materials and Technology 133(4): 041016.

54. Sciences EM (2012) EMS Catalog \#1232 Epofix Cold-Setting Embedding Resin.

55. A Organics (2014) Data Sheet - Aluminum powder, 99.97\% 200 mesh.
57. Y M Poon, C H Ho, Y W Wong, F G Shin (2007) Theoretical predictions on the effective piezoelectric coefficients of 0-3 PZT/Polymer composites. Journal of materials science 42(15): 6011-6017.

58. G Rujijanagul, S Boonyakul, T Tunkasiri (2001) Effect of the particle size of PZT on the microstructure and the piezoelectric properties of 0-3 PZT/polymer composites, Journal of materials science letters 20(21): 1943-1945.

59.ZY Liu, YY Wang, GS Huang, JR Wu (2008) Damping characteristics of chlorobutyl rubber/poly(ethyl acrylate)/piezoelectric ceramic/ carbon black composites. Journal of Applied Polymer Science 108(6): 3670-3676.

60.J Runt, E C Galgoci (1984) Polymer Piezoelectric Ceramic Composites - Polystyrene And Poly(Methyl Methacrylate) With Pzt. Journal Of Applied Polymer Science29(2): 611-617.

61. A Petchsuk, W Supmak, A Thanaboonsombut (2009) A Series of 0-3 Composites of Lead Zirconate Titanate and Ferroelectric Nylon77: Preparation and Electrical Properties. Journal of Applied Polymer Science 114(2): 1048-1054.

62.J Xu, KS Moon, C Tison, CWong (2006) A novel aluminum-filled composite dielectric for embedded passive applications. Advanced Packaging, IEEE Transactions on29(2): 295-306.

63. Nan CW, Shen Y, Ma J (2010) Physical properties of composites near percolation. Annual Review of Materials Research 40:131-151.

64. Sundar U, Cook-Chennault KA, Banerjee S, Refour E (2016) Dielectric and piezoelectric properties of percolative three-phase piezoelectric polymer composites. Journal of Vacuum Science \& Technology B, Nanotechnology and Microelectronics: Materials, Processing, Measurement, and Phenomena 34(4): 041232.

65. Berhan L, Sastry AM (2007) Modeling percolation in high-aspect-ratio fiber systems. I. Soft-core versus hard-core models. Phys Rev E Stat Nonlin Soft Matter Phys 75(4): 041120.

66. Berhan L, Sastry AM (2007) Modeling percolation in high-aspectratio fiber systems. II. The effect of waviness on the percolation onset. Physical Review E 75(4): 041121.

67. A M Sastry, C W Wang, L Berhan (2001) Deformation and failure in stochastic fibrous networks: Scale, dimension and application. In: Probabilistic Methods in Fatigue and Fracture. Soboyejo ABO (Ed). Key Engineering Materials, pp. 229-250.

68. YB Yi, Berhan L, Sastry AM (2004) Statistical geometry of random fibrous networks, revisited: Waviness, dimensionality, and percolation. Journal of Applied Physics 96(3): 1318-1327.

69. D J Bergman, Y Imry (1977) Critical behavior of the complex dielectric constant near the percolation threshold of a heterogeneous material. Physical Review Letters 39(19): 1222.

70.C Pecharromán, JSMoya (2000) Experimental evidence of a giant capacitance in insulator- conductor composites at the percolation threshold. Advanced Materials 12(4): 294- 297.

71. Banerjee S, Kappera R, Cook-Chennault KA, Chhowalla M (2013) Multi Walled Carbon Nanotube based Flexible Multi-morph Composite Thick Films with Graphene Electrodes. Science of Advanced Materials.

72.S Banerjee (2014) An experimental investigation of lead zirconate titanate-epoxy-multi-walled carbon nanotube bulk and flexible thick film composites. Rutgers University-Graduate School-New Brunswick.

73. Pedersen T, Hindrichsen CC, Thomsen E, Hansen K, Lou-Moller R (2007) Investigation of top/bottom electrode and diffusion barrier layer for PZT thick film MEMS sensors. in Sensors: 756-759

74. RA Matula (1979) Electrical resistivity of copper, gold, palladium, and silver. Journal of Physical and Chemical Reference Data 8(4): 11471298.

56. R A M (READE) (2012) Properties of Lead Zirconate Titanate. 
This work is licensed under Creative Commons Attribution 4.0 License

DOI: 10.19080/AJOP.2018.01.555574
Your next submission with Juniper Publishers will reach you the below assets

- Quality Editorial service

- Swift Peer Review

- Reprints availability

- E-prints Service

- Manuscript Podcast for convenient understanding

- Global attainment for your research

- Manuscript accessibility in different formats ( Pdf, E-pub, Full Text, Audio)

- Unceasing customer service

Track the below URL for one-step submission https://juniperpublishers.com/online-submission.php 